\title{
Demand in the Conditions of Heterogeneity of Goods and Consumers
}

\author{
Ismagilova G. N. ${ }^{1}$, Bagautdinova N. G. ${ }^{1} \&$ Safiullin L. N. ${ }^{1}$ \\ ${ }^{1}$ Institute of Management, Economics and Finance, Kazan Federal University, Kazan, 420008, Russia \\ Correspondence: Ismagilova G. N., Institute of Management, Economics and Finance, Kazan Federal University, \\ Kazan, 420008, Russia.
}

$\begin{array}{lr}\text { Received: March 10, } 2015 & \text { Accepted: March 31, } 2015 \quad \text { Online Published: April 30, } 2015 \\ \text { doi:10.5539/ass.v11n11p271 } & \text { URL: http://dx.doi.org/10.5539/ass.v11n11p271 }\end{array}$

\begin{abstract}
New results of research in the field of the theory of demand are presented in this article. Multidimensional additive and nonlinear models of interrelation of demand and its factors are introduced. The demand factors connected with qualitative and quantitative characteristics of economic category of demand are studied. An interconnection and functional dependences of demand on many factors, including amount of demand from quality and competitiveness of goods, and also from major factors of consumption are defined. The law of demand in space the price - quality-competitiveness is entered. Plenty of diagrams and examples are provided.
\end{abstract}

Keywords: price, consumer demand, quality, models of demand

\section{Introduction}

The use of diagrams in the field of research of demand was offered by the English economist A. Marshall. He introduced graphic dependences of amount of demand for the goods on its price in work "The principles of economy". Thus A. Marshall wanted to establish, at what price in the market of separate goods balance will be established. This circumstance forced him to consider the goods price $\mathrm{p}$ as function, and amount of demand for goods $\mathrm{Q}_{\mathrm{p}}$ as argument.

However demand is the broader concept depending on a set of factors having impact on demand of consumers. We from positions of joint consideration of demand and the competition suggest to enter into a set of known factors of demand one more important factor - quality of goods. Since A. Marshall's research till now property of goods, namely, quality of goods underwent strong change. Quality became more important than the price. As a result of it, there were new methods of the competition, including, non-price methods of the competition focused generally on quality of goods.

\section{Data and Methodology}

Demand is understood as reflection of needs of people for these or those goods, service, their desire to buy.

In this regard, we note in particular non-price competition. At non-price competition seek to change or improve qualitative characteristics of goods, "adjusting" thus, properties of goods to inquiries of consumers. As practice shows, change of quality indicators of goods leads to increase in demand for production of firm, it allows firm having economic profit due to increase of competitiveness of goods.

Processes of transformation of economy generated non-uniform consumers: very low provided, low-provided, average and highest levels of security very rich and thirsty part of society. If very low-provided part of the population uses goods of very poor quality and the price, for thirsty part (thirsty elite) demand is defined in a bigger measure not by the cost, not the price, but political and other interests, from nation-wide to global level. This part of people differs from average income not only wealth, but also psychologically. Being in financial position absolutely independent, the thirsty elite thinks of other categories.

Thus, in the course of economic transformations consumers were very strongly stratified, i.e. became non-uniform that also demands further development of the theory of demand.

Therefore the volume of demand has to be defined not only by the price, but also by the maximum opportunities of the buyer or the maximum readiness to pay for this quality of the goods capable to satisfy his requirements. Size (or volume) of demand depends not only on the price, it depends also on the maximum amount of a good. And this good is defined by a level of quality of goods which the buyer (buyers) can get for some period of time under existing conditions. 
The set of the factors having impact on the volume of demand (offer) we will call a space of factors of demand (offer).

Further we will conduct a statement of material concerning demand volume, assuming a specular reflection on offer volume.

Each factor possesses a set of values for which in multidimensional systems of coordinates, for example, in the Cartesian a certain axis is allocated. Thus the volume of demand forms the surface characterizing demand. Such surface, following a demand curve, is called a demand surface. The concept of surface of demand was used in S.G. Svetunkov's work. If demand depends on one factor, for example, in the plane volume - price we receive the graph of a curve of demand. In case of consideration of volume of demand from any two factors on graphics the volume of demand forms a surface.

For example, demand volume in space the price - income is under construction on the planes of three-dimensional space. The demand surface in n-dimensional space of factors is under construction on the planes of $n+1$-dimensional space. From the geometrical point of view such surface forms a hypersurface. Visually demand volume from two factors can be presented in three-dimensional space. To display demand in space more than three - two factors it is necessary to have its multidimensional functional dependence.

Determinants of demand are the major factors determining demand size. They are subdivided into two big groups - price and non-price.

The following price factors belong to the first group of determinants of demand:

- price of these goods;

- the prices of the goods replacing this good in consumption or goods substitutes (interchangeable goods);

- the prices of the goods supplementing this good in consumption or the complementary goods (complementary goods).

In our opinion, demand volume significantly depends on quality of these goods, quality of goods substitutes, on quality of the complementary goods. Therefore in addition we suggest to enter into the second group of determinants:

- quality of these goods, quality of interchangeable and quality of complementary goods;

also we will allocate the known factors of demand influencing a choice of the buyer:

- income of consumers, consumer requirements for quality, tastes and preferences of consumers, objective, natural and external conditions of consumption and expectation of consumers.

Thus, the size of demand, its structure and dynamics depend on numerous factors. We will use thus the following designations: Price and qualities of these goods $\mathrm{p}$ and $\mathrm{g}$.

The prices and quality of the goods replacing these goods in consumption or goods substitutes (interchangeable goods) $p^{s}=\left(p_{1}^{s}, p_{2}^{s}, \ldots, p_{n}^{s}\right)$ и $g^{s}=\left(g_{1}^{s}, g_{2}^{s}, \ldots, g_{n}^{s}\right), \mathrm{p}^{\mathrm{s}}$ и $\mathrm{g}^{\mathrm{s}}$ - vector sizes of the price and quality of goods substitutes, and $\mathrm{p}_{\mathrm{i}}^{\mathrm{s}}$ и $\mathrm{g}_{\mathrm{i}}^{\mathrm{s}}$ - elements of these vectors, i.e. price and quality i- nth interchangeable goods.

The prices and qualities of the goods supplementing this good in consumption or the complementary goods (complementary goods) $p^{c}=\left(p_{1}^{c}, p_{2}^{c}, \ldots, p_{m}^{c}\right)$ and $g^{c}=\left(g_{1}^{c}, g_{2}^{c}, \ldots, g_{m}^{c}\right)$, pс и gc - vector sizes of the price and quality of the complementary goods, and $\mathrm{p}_{\mathrm{i}}^{\mathrm{c}}$ и $\mathrm{g}_{\mathrm{i}}^{\mathrm{c}}$ - elements of these vectors, i.e. price and quality i-nth complementary goods.

1. The income of the consumer allocated for purchase of these goods $\mathbf{y}_{\Pi}$.

2. Tastes and preferences of the consumer $\mathrm{z}_{\Pi}$.

3. Objective, natural, external conditions of consumption $\mathrm{x}_{\Pi}$.

4. Expectations of consumers $\mathrm{e}_{\Pi}$.

The listed factors are generally vector quantities. In known works on the economic theory among the factors influencing a choice of buyer, demand volume, i.e. a quality factor obviously isn't considered. In our opinion, demand volume significantly depends on quality of goods. Therefore we entered into a set of factors of demand also a quality factor, i.e. quality of goods, quality of the interchanging and complementary goods. We will consider the most general, than in known works expression of volume of demand in the form of the following functional communication:

$$
Q^{D}=f\left(p, g, p^{s}, g^{s}, p^{c}, g^{c}, y_{\Pi}, z_{\Pi}, x_{\Pi}, e_{\Pi}, k\right)
$$


As follows from this expression, the volume of demand depends on the price, quality, the price and quality of all goods - substitutes, the price and quality of all complementary goods, the income of the consumer allocated for purchase of these goods, tastes, requirements of quality and preferences of consumers, conditions of consumption and expectation of consumers. Here we could include some more factors influencing demand volume. However because of the growth of dimension of the specified factors and sufficiency of these factors for disclosure of full economic essence of demand in multidimensional space of factors we consider these factors sufficient.

Among these factors are both independent, and interconnected factors. First of all, the price and quality of goods belong to interconnected factors. Thus we will note that in references known to us the specific type of function of demand in multidimensional space of factors is absent. Below we offer effective methodology of synthesis or designing of multidimensional function of demand.

\section{Results (Obligatory)}

Additive models of demand in multidimensional space of factors.

We can consider well-known results of marginalists' theory of utility as some particular case, i.e. consider utility like function of two variables - quantity and quality, but with fixed invariable quality, i.e. $U=U(g, Q), g=$ const.

Additive models of demand in multidimensional space of factors.

The simplest model of demand in multidimensional space of factors is the additive model of demand. Such model reflects the valid position of demand better than demand model depending on one factor - the price, defined at constancy of other conditions. It is connected with that influence of separate factors of demand as it was shown by us at research of "other conditions", in the real market impossible to control, i.e. it isn't possible to provide equality of all of "other conditions" in case of an assessment of influence of one studied factor - the price.

To reveal influence of a set of factors on demand and in particular influence of the following major factors: the goods price (p), quality of goods (g), the income of the consumer (y) allocated for purchase of these goods, tastes and preferences of the consumer (z), objective and natural external conditions of consumption ( $\mathrm{x}$ ) and expectations of consumers (e) we will construct the demand equation for these factors:

$$
Q^{D}=Q_{1}^{D}+Q_{2}^{D}+\ldots+Q_{i}^{D}+\ldots+Q_{I}^{D}
$$

where $Q_{i}^{D}=Q_{i}^{D}\left(x_{i}\right)$ - the volume of demand on i-nth фактору, I - number of the factors influencing demand of consumers.

For the listed six factors in case of linearity of demand from each factor, additive demand is represented the following way:

$$
Q=a_{0}-a_{1} p+a_{2} g \pm a_{3} y \pm a_{4} z \pm a_{5} x \pm a_{6} e
$$

where $\mathrm{a}_{0}$ - free coefficient of the equation which characterizes influence on demand of all of other, except the listed factors. Other coefficients ai are determined as private derivatives of demand by the corresponding factors. They can be found by method of the smallest squares. Signs (+) and (-) before coefficients of $a_{i}$ specify the direction of influence of each factor on demand. They are defined by the developed conditions in the market, i.e. depend on market condition.

From the first and in particular from the second equation can be received as special cases of graphics of change and shift of curves of demand of A. Marshall. And at known coefficients of the equation of demand it is possible to point the size of change or shift of a curve of demand at the price concerning this or that separately taken factor at constancy of other four factors, or at change of all five factors on specific values.

When using additive model the volume of demand is equal to the algebraic sum of volumes of demand from each factor influencing a choice of the buyer. In this case the factors are assumed to be not correlated. For example, demand volume at the price and quality is presented in the form of the algebraic sum of price volume of demand $D_{p}$ and demand volume on quality $D_{g}$ of the good:

$$
Q^{D}=D_{p}+D_{g}
$$

at constancy of all other factors. 
The additive model is convenient in primary analysis of demand from various factors, i.e. by consideration of demand from each factor, i.e. when studying a contribution of separately taken factor.

Non-additive models of demand are more perspective as each factor can be considered only in connection with other factors of demand. Cumulative consideration of the different interconnected factors of demand generates qualitatively new functional properties of demand which isn't reducing to the sum of properties of its components.

The generalized demand models in multidimensional space of factors.

1. Construction or synthesis of model of demand in space of many interconnected factors demands the accounting of the following economic situations:

2. Factors of demand have to reflect an environment of the specific market.

3. Direction of influence of each factor on demand of the buyer.

4. Level of interrelation of factors, i.e. it is necessary to consider not only the directions of factors on demand, but also their interaction. Thus consideration joins interaction of demand of the first order (interaction of two factors), interaction of demand of the second order (interaction of three factors) and interaction of a high order, for example $\mathrm{n}$-th order (interaction of $\mathrm{n}+1$ factors),

Interaction of factors in known works is described as a product of two, three and more factors $\left(\mathrm{x}_{1} \mathrm{x}_{2}, \mathrm{x}_{1} \mathrm{x}_{2} \mathrm{x}_{3} ; \ldots\right.$, $\left.\mathrm{x}_{1} \mathrm{x}_{2} \mathrm{x}_{3} \ldots \mathrm{x}_{\mathrm{n}+1}\right)$.

Representation of interrelation of factors in the form of works shows existence of direct link between factor and demand. However factors and demand can have both direct, and inverse relationship therefore we suggest to bring interrelations of a type $\left(\mathrm{x}_{1} / \mathrm{x}_{2}, \mathrm{x}_{1} \mathrm{x}_{2}\right)$ - first-order interaction, $\left(\mathrm{x}_{1} / \mathrm{x}_{2} \mathrm{x}_{3}, \mathrm{x}_{1} \mathrm{x}_{2} / \mathrm{x}_{3}, \ldots \mathrm{x}_{3} / \mathrm{x}_{1} \mathrm{x}_{2}\right.$ и $\left.\mathrm{x}_{1} \mathrm{x}_{2} \mathrm{x}_{3}\right)$-the second order interaction. In our case the factors having direct impact on demand register in numerators, and the factors which are in inverse relationship with demand settle down in denominators. Both in numerators, and in denominators there can be also more difficult functions from the considered factors.

5. Factors have to be quantitatively measured. If it is necessary to include the qualitative factor which doesn't have quantitative measurement in model, they need to give quantitative definiteness. For overcoming of uncertainty of the concept "qualities" of goods we offered special methods of measurement of quality. They are based on a basis of use of economic sense of this concept.

6. If factors $\mathrm{x}_{\mathrm{i}} и \mathrm{x}_{\mathrm{j}}$ are independent from each other, for them the order of interaction is absent.

7. Thus, the structure of volume of demand in multidimensional space of factors includes one-factorial volumes of demand and combinational factorial demands.

8. The one-factorial volume of demand represents the demand volume depending on one factor and determined in a condition of constancy of all other other factors. Their economic sense is that how each factor influences demand of the consumer. The one-factorial volume of demand is described by function of one variable.

9. Combinational factorial demands consist of volumes of demand of the first, second and higher orders of interaction determined respectively by a combination and interaction of two, three, etc. factors. The volume of demand of the first order of interaction is described by two-dimensional function, the second order of interaction - three-dimensional function, and demand volume of $n$-th order is described $n+1$ dimensional function.

10. Apparently, there is an optimal value of the order of demand. In practice, the value of the order of interaction of demand ranges from the first-order interactions up to the third.

11. Taking into account the specified requirements and explanations to synthesis of model of demand it is possible to formulate demand in multidimensional space as follows. The demand volume depending on many factors is equal to the algebraic sum of volumes of all one-factorial and combinational factorial demands. Combinational factorial demands make a share of the demand characterized by joint impacts on a choice of the buyer of several factors at the same time. Demand volume in space of many factors is described by the following expression:

$$
Q^{D}=\sum_{i=1}^{I} Q_{i}^{D}+\sum_{i=1}^{I} \sum_{j=i+1}^{I} Q_{i j}^{D}+\sum_{i=1}^{I} \sum_{j=i+1 k=j+1}^{I} \sum_{i j k}^{I} Q^{D}+\ldots
$$


where - $i$ - th the one-factorial volume of demand determined by $i$-th factor; - the volume of demand of the first order caused by joint influence $i$-th and $j$-th factors $x i$ and $x j$; - volume of factorial demand of the second order of interaction i-th, j-th, $\mathrm{k}$-th factors $\mathrm{xi}, \mathrm{xj}$ and хк. Factorial demands of the orders of interaction first, second, third, etc. are called by us combinational factorial demands. We will note that one-factorial volumes of demand can be considered as combinational factorial demands of a zero order of interaction.

As an example we will consider demand in space of two factors - the price and quality.

Table 1. Market situation and components of nonlinear model of demand

\begin{tabular}{|c|c|c|c|c|c|c|c|}
\hline & Factors & $\begin{array}{l}\text { Price } \\
(p)\end{array}$ & $\begin{array}{l}\text { Quality } \\
\qquad(g)\end{array}$ & $\begin{array}{c}\text { Income of } \\
\text { consumers } \\
(y)\end{array}$ & $\begin{array}{c}\text { Tastes and } \\
\text { preferences of } \\
\text { consumers }(z)\end{array}$ & $\begin{array}{c}\text { External } \\
\text { conditions of } \\
\text { consumption }(x)\end{array}$ & $\begin{array}{c}\text { Expectation } \\
\text { of consumers } \\
(e)\end{array}$ \\
\hline \multicolumn{2}{|c|}{$\begin{array}{l}\text { Direction of influence } \\
\text { of a factor on the offer }\end{array}$} & Inverse & Direct & Direct & Direct & Inverse & Inverse \\
\hline \multirow{2}{*}{1} & \multirow{2}{*}{ Price $(p)$} & $Q_{l}(p)$ & $Q_{12}(p, g)$ & $Q_{13}(p, y)$ & $Q_{14}(p, z)$ & $Q_{15}(p, x)$ & $Q_{16}(p, e)$ \\
\hline & & $a_{1} / p$ & $a_{12} g / p$ & $a_{13} y / p$ & $a_{14} z / p$ & $a_{15} / p x$ & $a_{16} / p e$ \\
\hline \multirow{2}{*}{2} & \multirow{2}{*}{ Quality $(g)$} & & $Q_{2}(g)$ & $Q_{23}(g, y)$ & $Q_{24}(g, z)$ & $Q_{25}(g, x)$ & $Q_{26}(g, e)$ \\
\hline & & & $a_{2} g$ & $a_{23} g y$ & $a_{24} g z$ & $a_{25} g / x$ & $a_{26} g / e$ \\
\hline \multirow{2}{*}{3} & Income of & & & $Q_{3}(y)$ & $Q_{34}(y, z)$ & $Q_{35}(y, x)$ & $Q_{36}(y, e)$ \\
\hline & consumers $(y)$ & & & $a_{3} y$ & $a_{34} z y$ & $a_{35} y / x$ & $a_{36} y / e$ \\
\hline \multirow{2}{*}{4} & Tastes and & & & & $Q_{4}(z)$ & $Q_{45}(z, x)$ & $Q_{46}(z, e)$ \\
\hline & consumers $(z)$ & & & & $a_{4} z$ & $a_{45} z / x$ & $a_{46} z / e$ \\
\hline \multirow{2}{*}{5} & External & & & & & $Q_{5}(x)$ & $Q_{56}(x, e)$ \\
\hline & $\begin{array}{l}\text { conditions of } \\
\text { consumption }(x)\end{array}$ & & & & & $a_{5} / x$ & $a_{56} / x e$ \\
\hline \multirow{2}{*}{6} & Expectations of & & & & & & $Q_{6}(e)$ \\
\hline & consumrs $(e)$ & & & & & & $a_{6} / e$ \\
\hline
\end{tabular}

The specific market situation, one-factorial and combinational components of factorial demand formed of six factors is presented in Table 1. Combinational components of factorial demands are located above the diagonal elements formed of one-factorial demands.

The market situation is formed of six factors: the price, quality of goods, the income of consumers, tastes and preferences of consumers, objective, natural created external conditions of consumption and expectation of consumers make the return impact on demand volume.

1. We will assume that one-factorial models of demand from the price and quality are described by linear functions. Then taking into account the direction of influence of the price and quality on demand the equation (3.5) can be written as

$$
Q^{D}=a_{0}-\frac{a_{1}}{p}+a_{2} g+a_{3} \frac{g}{p}
$$

2 Demand in space of two factors - the price and the income of consumers is recorded by the following equation:

$$
Q^{D}= \begin{cases}a_{0}+\frac{a_{1}}{p}+a_{2} y+a_{3} \frac{y}{p}, & y \leq y_{0}, \\ a_{0}+\frac{a_{1}}{p}+\frac{a_{2}}{y}+\frac{a_{3}}{y p}, & y>y_{0} .\end{cases}
$$

This equation shows that demand of the consumer under a condition $y \leq y 0$ will increase, and then the consumer with increase in the income, i.e. with $y>y 0$ switches from one good to another, for example, on good with higher 
quality. Then demand for the first good with growth of the income decreases, as the second branch of the equation describes.

We will take a closer look at one-factorial volumes of demands from factors of the price and quality, and also demand volume in space-price-quality-competitiveness.

\section{References}

Aghion, P., \& Tirole, J. (1997). Formal and real authority in organizations. Journal of Political Economy, 105(1), $1-29$.

Anderson, E. W., Fornell, C., Lehmann, D. R., \& Sullivan, M. W. (1993). The antecedents and consequences of customer satisfaction for firms. Marketing Science, 12(2), 125-143.

Bagautdunova, N. G., Safiullin, L. N., Safiullin, N. Z., \& Novenkova, A. Z. (2012). Theoretical aspects of public welfare rise. Proceedings 2nd Annual International Conference on Micro and Macro Economics (pp. 77-81).

Bolton, R. N., \& Lemon K. N. (1999). A dynamic model of customers' usage of services: Usage as an antecedent and consequence of satisfaction. Journal of Marketing Research, 36(2), 171-186.

Cadotte, E. R., Woodruff, R. B., \& Jenkins R. L. (1987). Expectations and norms in models of consumer satisfaction. Journal of Marketing Research, 24, 305-314.

Deming, W. E. (1982). Quality, Productivity, and Competitive Position. Cambridge, MA: MIT Press.

Gambu, M. (1988). Klaster analisys (p. 342). Finace.

Isikava, K. (1998). Japanese method of quality (p. 215).

Juran, J. M. (1992). Juran on Quality by Design: The New Steps for Planning Quality into Goods and Services. New York: The Free Press.

Laffont, J.-J. (1989). The Economics of Uncertainty and Information. The MIT Press, Cambridge, MA

Laffont, J.-J., \& Martimort, D. (2002). The Theory of Incentives: The Principal-Agent Model. Princeton University Press, Princeton, NJ.

Macho-Stadler, I., \& Pérez-Castrillo, J. D. (2001). An Introduction to the Economics of Information: Incentives and Contracts (2nd ed.). Oxford: Oxford University Press.

Marshall. (1983). Principles of Economics (6th ed.).

Morgan, N. A., \& Vorhies, D. W. (2001). Product quality alignment and business unit performance. Journal of Product Innovation Management, 18(6), 396-407. http://dx.doi.org/10.1016/S0737-6782(01)00112-6

Nelson, P. (1970). Information and consumer behavior. Journal of Political Economy, 78(2), 311-329.

Safiullin, L. N., Ismagilova, G. N., Safiullin, N. Z., \& Safiullin, M. R. (2012). Estimation of quality of the goods and satisfaction of consumers. Proceedings 2nd Annual International Conference on Micro and Macro Economics (pp. 61-63).

Tirole, J. (1988). The Theory of Industrial Organization. Cambridge, MA: MIT Press.

\section{Copyrights}

Copyright for this article is retained by the author(s), with first publication rights granted to the journal.

This is an open-access article distributed under the terms and conditions of the Creative Commons Attribution license (http://creativecommons.org/licenses/by/3.0/). 